\title{
Foods Used as Ethno-medicine in Jammu
}

\author{
Hemla Aggarwal* and Nidhi Kotwal** \\ *Department of Food Science \& Technology, Govt. College for Women Gandhinagar, \\ Jammu, Jammu and Kashmir, India \\ **Govt. College for Women, Parade, Jammu, Jammu and Kashmir, India \\ E-mail: nidhikotwal@yahoo.co.in
}

KEYWORDS Ethno-medicine. Foods. Fruits. Vegetables. Spices

\begin{abstract}
Research on food used as ethno medicine has drawn comparatively lesser attention as a research field in $J \& K$ in comparison to the other States. Plant foods have been of great help to mankind in relieving many diseases from earliest times. In recent years scientists have found that some foods frequently over looked, even some once considered bad for us - actually may help prevent everything from cancer to heart problems. The present study was conducted to study the various foods used as ethno medicine in Jammu The sample consisted of 200 adults in the age group of 18-45 years of age. The different traditional foods such as Turmeric, Rock, Salt, Mint, Onion, Ginger, Ajwain, Fennel, Cumin, Cardamom, Cloves, Asafetida, Garlic, Honey, Pomegranate, Dates, Bitter Gourd and Raisins were used to help in management of various ailments at home by most of the subjects.
\end{abstract}

\section{INTRODUCTION}

The plant foods have been of great help to mankind in relieving many diseases from earliest times. Primitive people in all ages have some knowledge of medicinal plants. "Sugar and spice and all that is nice" is a well-known expression of spices, is a well-known expression of appreciation. India is known as the home of spices, it also has a rich heritage of traditional systems of medicine in which spices do occupy a prime place. Spices and condiments are optional choices in the preparation of our food. Spices flavour our food, are used in cosmetics and are used as medicine. They are of plant origin such as floral parts fruits or berries, seeds, rhizomes, roots, leaves or bulb and bark. Majority of them are cultivated in India. Spices besides their application as food flavoring and colouring agents, also have medicinal properties. Spices stimulate salivation and aid in secretion of amylase, neuramenic acid and hexosamines. Spices increase secretion of saliva, which contains more of ptyalin so that carbohydrates are easily digested. Some spices have anti-inflammatory and anti-bacterial and anti- oxidant properties. Most recently some of them have been discovered to have anticancer effect (Reddy 1993).

Apart from spices other foods like Arhar-dal seeds are used in snakebite. Soya bean is beneficial for person suffering from diabetes and hypertension. Masur dal seeds are used as laxative during constipation and other disorders. When made into paste, it is applied on ulcers. Almonds are considered as demulcent, stimulant and used as nervine tonic. Onion is considered stimulant, diuretic and expectorant, used against flatulence and dysentery. Carrot seeds are carminative; they are useful in diseases of kidney and in dropsy. Spinach seeds are used as laxative, cooling and are used in difficult breathing, inflammation of liver and in jaundice. The juice of bitter gourd is used in snakebite and in diabetes. The fruits and leaves are useful in piles, jaundice, leprosy and vermifuge. Coccinia leaves and root's juice is used in diabetes and leaves are applied in skin eruptions.(Pattanayak 1986.)

In recent years scientists have found that some foods frequently over looked even some once considered bad for us - actually may help prevent everything from cancer to heart problems. Avocados are found to lower. The cholesterol and LDL levels. Orange marmalades rich in flavonoids lowered the toxic compounds in those having gastric cancer and healthy stomach. Once a week serving of salmon can dramatically cut risk of coronary heart disease, gobbling nuts down - one serving are good way to keep cholesterol at bay and lower risk of heart attack. Bean chili binds onto cholesterol we eat, and hence lowers the cholesterol levels (Holman 1996).

Easwaran and Goswami (1989) studied nutritive value of selective 15 unconventional plant foods consumed by Khasis of Meghalaya. Rice was the staple cereal of the Khasis. Cent percent of the population were non--vegetarian. Besides the normal flesh foods, rats, tadpoles, ant's eggs were also consumed; the unconventional plants 
consumed by the Khasis tribe are rich in energy and other nutrients. In addition to the nutritive value they have been found to have medicinal values, which require further research study for confirmation. The present study was conducted to study the various foods used as ethno medicine in Jammu city. The objective of the study was

1. To study the various herbs and spices used as ethno medicine in Jammu city

2. To study the various fruits and Vegetables used as ethno medicine for various ailments in Jammu city.

\section{METHODOLOGY}

The study was undertaken in 2002, to investigate the usage of various foods used as ethno medicine in Jammu province. The sample consisted of 200 adults in the age group of 18-45 years of age drawn by using purposive sampling from Jammu city. An interview schedule was formulated to elicit information from the respondents about the medicinal uses of different herbs, spices, vegetables and fruits.

\section{RESULTS AND DISCUSSIONS}

The results of the survey showed that in most of the homes of the selected subjects $(90 \%)$, one food item or the other was used as medicine or remedy of disease (Table 1 ).

Table 1: Food used as ethno medicine

\begin{tabular}{lrl}
\hline Responses & No. & $\%$ \\
\hline Yes & 180 & 90 \\
No & 20 & 10 \\
\hline
\end{tabular}

It is clear from table 2 The food items used to cure small ailments at home level included Turmeric (Haldi), Rock Salt (Kala Namak), Mint (Pudina), Onion (Payaz), Ginger (Adrak), Caraway (Ajwain), Fennel (Saunf), Cumin (Zeera),) Cardamom (Harielaichi) Cloves (Loung), Asafoetida (Hing) Garlic (Lasun), Honey (Shahad) Saffron (Kesar), Fenugreek Seeds (Methi dana), Bitter Gourd (Kerela) Raisins (Sogi), Brinjal (Baigan) Dried Fish (Sukhi Machi), Indian Gooseberry (Amla), Isabgol Papaya (Papita), Pumpkin (Peela K used $a d u$ ), Pomegranate (Anar) and Dry Dates (Chuare). According to Hacohen (2000) in Israeli traditional medicine, the local medicinal plants are wild, and far fewer like: almonds, apple, beet, carrot, eggplant, garlic, lettuce, olive, onion, pomegranate, quince, radish, and spinach are cultivated

\section{Spices}

Turmeric (Curcuma longa): Majority of the

Table 2: Food Items used as medicine for different remedies $(\mathrm{n}=180)$

\begin{tabular}{|c|c|c|c|c|}
\hline S. No. & Food Items (Herbs and Spices) & Remedies & No. & $\%$ \\
\hline 1 & Turmeric (Haldi) & Antiseptic & 180 & 100.0 \\
\hline 2 & Rock Salt (Kala Namak) & Goiter, Stomach problems & 108 & 60.0 \\
\hline 3 & $\begin{array}{l}\text { Mint (Pudina), Onion (Payaz), Ginger } \\
\text { (Adrak), Caraway (Ajwain), Fennel (Saunf), } \\
\text { Cumin (Zeera), ) Cardamom (Harielaichi) } \\
\text { Cloves (Loung) }\end{array}$ & Digestive problems & 108 & 60.0 \\
\hline 4 & Asafoetida (Hing) & Flatulence; constipation & 108 & 60.0 \\
\hline 5 & Garlic (Lasun) & Hypertension, Stomach problems & 115 & 63.9 \\
\hline 6 & Honey (Shahad) & Sore Throat, Stomach Problems & 180 & 100.0 \\
\hline 7 & Saffron (Kesar) & Low Blood Pressure & 45 & 25.0 \\
\hline 8 & Fenugreek Seeds (Methi dana) & Diabetes, Hypertension & 16 & 8.9 \\
\hline S. No. & Food Items (Fruits and Vegetables)) & Remedies & No. & $\%$ \\
\hline 1 & Bitter Gourd (Kerela) & Diabetes & 117 & 65.0 \\
\hline 2 & Raisins (Sogi) & Cough, cold Hypertension & 114 & 63.3 \\
\hline 3 & Brinjal (Baigan) Dried Fish (Sukhi Machi) & Goiter & 12 & 6.6 \\
\hline 4 & Indian Gooseberry $(A m l a)$ & Bleeding gums, Cancer & 54 & 30.0 \\
\hline 5 & Isabgol & Digestive problems & 72 & 40.0 \\
\hline 6 & Papaya (Papita), Pumpkin (Peela Kadu) & Diarrhea & 81 & 45.0 \\
\hline 7 & Pomegranate (Anar),Dry Dates (Chuare) & Anemia & 126 & 70.0 \\
\hline
\end{tabular}

- Multiple choices 
subjects, mostly for its antiseptic properties, consumed turmeric(Haldi) every day in the vegetable and pulse preparation. It was also given in boiling hot milk with ghee during injury. Turmeric was thought to be antiseptic along with a property to heal the wounds fast. The subjects also applied it on the open wounds as a first aid in any wound or injury. Turmeric is used during stomachache, as tonic and blood purifier. It was mixed with warm milk and consumed during common cold. Externally it was applied on ulcers and its paste with lime was a remedy for inflamed joints. Turmeric has been demonstrated to have antitumour effect in animals treated with potent carcinogens (Polasa 1993). Turmeric is also used as stimulant and depurative. It contains essential oil and crystalline coloring matter curcumin (Pradhan 1995).

Rock Salt: Rock salt (Kala Namak) was taken by $60 \%$ of the subjects during stomach problems. It was also considered to cure goiter.

Mint (Pudina) Lamiaceae, Onion (Payaz) Aspergillus, Ginger (Adrak) Zingiber officinale, Caraway (Ajwain) Trachyspermum ammi syn. Carum copticum, Fennel (Saunf), Cumin (Zeera) uminum cyminum Linn, Cardamom (Hari elaichi) Elettaria cardamomum, Cloves (Loung) Syzygium aromaticum, syn. Eugenia aromaticum or Eugenia caryophyllata: These were included in the list of foods used to cure one or other stomach or gastrointestinal problems by most of the subjects $(60 \%)$ at home level. Caraway seeds, coriander seeds and cloves were consumed by the subjects along with water during indigestion, stomachache and belching. They were thought to be carminative, stimulant, ant flatulent and ant emetic and hence consumed after meal to aid the digestion.

The medical uses of cloves are many. They are carminative, stimulant, antiflatulent and ant emetic. They are also used in various forms of dyspepsia and gastric irritation (Lakshmaiah, 1996). Consumption of cloves increased the brain power was a concept prevalent amongst the selected subjects. Studies reveal that cumin seeds are used as an ingredient in many ayurvedic medicines. It is carminative and useful in dyspepsia and diarrhea. Ginger is given in dyspepsia and colic. Cardamom is used chiefly for relieving flatulence or feeling of over fullness of stomach, i.e. to promote digestion. It is administered with purgatives, and as a flavoring agent. Powdered with cloves, ginger and caraway, it is good in indigestion (Pradhan 1995; Manay 1996).
Aesfoetida (Ferula assa-foetida L.): Aesfoetida (Hing) was used by $60 \%$ of the respondents to cure flatulence and constipation.

Honey: Honey (Shahad), was used for treatment of many ailments especially in throat and stomach problems. Pure honey is readily available in the Doda, Udhampur and Poonch districts and is used from scarcely to lavishly depending on the socio - economic status of the person. According to the subjects honey has antiseptic, antibacterial and curative properties. Honey, ginger juice and black pepper powder was consumed during sore throat by the subjects. Fishman et al. (1993). In a study found that Herbal teas, especially oregano, cinnamon, eucalyptus, and chamomile (sometimes with honey), Honey and lemon were used to cure cough in Mexico.

Saffron (Crocus sativus): Saffron (Kesar) is an additive and is used in preparation of many dishes viz, kehwa, pulao, sweetmeats and yoghurts in Jammu and Kashmir. It is known for its flavour and property of raising blood pressure. It was also consumed in the event of low blood pressure by $(25 \%)$ subjects.

Fenugreek Seeds (Trigonella foenumgraecum): Fenugreek seeds were consumed by very few of the subjects $(8.9 \%)$ who were diabetic. About one teaspoon of fenugreek seeds were soaked overnight and consumed early morning on empty stomach with a glass of water. The fenugreek seeds were consumed to lower the blood sugar levels. Studies also suggest that defatted Fenugreek seeds cause hypoglycemic effect in both diabetic and normal subjects (Rishi 1989).

\section{Fruits and Vegetables}

Garlic (Allium sativum): Garlic has a strong flavour due to the sulphur containing allicin. It has also antibacterial and anti-insecticide activities. (63.9\%) subjects used garlic as a remedy for a number of ailments and physiological disorders. It was taken by the subjects to decrease the cholesterol content of the serum and reduce hypertension. Garlic was also used to treat various digestive disorders. It was supposed to act as a gastric stimulant and aided in digestion of fatty meal. Garlic's antibacterial properties, have been described by Louis Pasteur (Polasa 1993). Studies have shown that consumption of garlic reduces the blood cholesterol level (Rishi 1989). 
Bitter Gourd (Momordica charantia): Juice of Bitter gourd was consumed by most of the subjects $(65 \%)$, to lower their blood sugar levels. The juice of the bitter gourd was extracted and consumed without dilution. In a study kerela juice was found to decrease the blood glucose level in the diabetics (Rishi 1989).

Raisins (Vitis vinifera): Raisins were consumed by $(63.3 \%)$ of the subjects, to lower their hypertension. Raisins were consumed after frying it in desi ghee to cure chronic cough.

Brinjal (Solanum melongena) and Dried Fish:_Brinjal and dried fish were consumed by only $(6.6 \%)$ percent of the subjects; these were believed to be rich in iodine and were consumed by the subjects suffering from goiter.

Indian Gooseberry (Emblica officianalis): Amla was consumed by $30 \%$ of the subjects for the treatment of bleeding gums and cancer. Amla fruit finds a number of medicinal uses in indigenous medicine (Manay 1996).

Isabgol (Plantago ovata): Isabgol was taken along with curd during diarrhea and with milk during constipation by less than half of the subjects (40\%). Isabgol has been reported to be very useful in several kinds of chronic dysentery, such as of amoebic and bacillary origin and chronic diarrheas. It is useful as a soothing agent for mucous membranes, and is useful in constipation (Jain 1968).

Papaya (Carica papaya), Pumpkin (Cucurbita Moschata Duch): Papayas and pumpkins were also used to cure certain digestive disorders at home level, by (45\%) of the subjects. In chronic diarrhea papaya was used to cure the ailment.

Pomegranate (Punica granatum), Dry Dates (Phoenix dactilifera): Pomegranate (Anar) and dates (Chuare) were taken by (70\%) subjects to raise their hemoglobin level.

\section{CONCLUSION}

The different traditional foods were used to help in management of various ailments at home by most of the subjects. It is desirable to use traditional foods as medicines, which our grandmothers also practiced. Latest researches have proven the importance of many of these traditional foods. Therefore it is highly desirable that programmes be launched to popularize cultivation and consumption of such therapeutic foods of proven effectiveness.

\section{REFERENCES}

Easwaran P, Goswami B 1989. Nutritive Value of Selected 15 Un-conventional plant foods consumed by Khasis of Meghalaya. The Indian Journal of Nutrition and Dietetics; 26: 62-67.

Fishman BM, Bobo L, Kosub K, Womeodu RJ 1993. Cultural issues in serving minority populations: Emphasis on Mexican Americans and African Americans. Am J Med Sci, 306(3):160-166.

Hacohen D 2000. Immigration and absorption, Trends in Israeli Society, 2001: 419-423.

Holman Jennifer Reid 1996. Seven Wonder Foods to protect your heart. Readers Digest. American Edition Feb. 2000

Jain SK 1968. Medical Plants, India-Thailand and the People. New Delhi: National Book Trust.

Lakshmaiah N 1996. Clove and its active principle engenol. Nutrition News NIN Hydrabad, 17: 3.

Manay NS 1996. Food Facts and Principles. New Delhi. New Age International Publishers.

Pattanayak DP 1986. Tradition and Food. WHO Techn Rep Ser No. 732, Geneva: WHO

Polasa K 1989. Role of anticarcinogens in diet. Nutrition News. NIN Hydrabad, 10(5): 4.

Pradhan, S. 1995. Economic Botany. New Delhi: Har Anand Publications.

Reddy V 1993. Nutrition Trends in India. NIN, ICMR, NNHM, Report of Repeat Surveys (1988-90). NNHB Report on Urban Population.

Rishi P 1989. Dietetic Internship and Effect of Fenugreek Seeds on the Plasma Glucose and Cholesterol Levels of NIDDM Subjects. M.Sc Dissertation. L.I.C. Delhi: University of Delhi. 